\section{Origin of the bright photoluminescence of few-atom silver clusters confined in LTA zeolites}

\author{
Didier Grandjean $^{1 *}$, Eduardo Coutiño-Gonzalez ${ }^{2}$, Ngo Tuan Cuong ${ }^{3,4}$, Eduard Fron², \\ Wouter Baekelant $^{2}$, Saleh Aghakhani', Philomena Schlexer ${ }^{5}$, Francesco D'Acapito ${ }^{6}$, \\ Dipanjan Banerjee ${ }^{7}$, Maarten B. J. Roeffaers ${ }^{8 *}$, Minh Tho Nguyen ${ }^{4}$, \\ Johan Hofkens ${ }^{2}$, Peter Lievens ${ }^{1 *}$
}

Silver (Ag) clusters confined in matrices possess remarkable luminescence properties, but little is known about their structural and electronic properties. We characterized the bright green luminescence of $\mathrm{Ag}$ clusters confined in partially exchanged $\mathrm{Ag}$-Linde Type A (LTA) zeolites by means of a combination of x-ray excited optical luminescence-extended $x$-ray absorption fine structure, time-dependent-density functional theory calculations, and time-resolved spectroscopy. A mixture of tetrahedral $\mathrm{Ag}_{4}\left(\mathrm{H}_{2} \mathrm{O}\right)_{x}{ }^{2+}(x=2$ and $x=4)$ clusters occupies the center of a fraction of the sodalite cages. Their optical properties originate from a confined two-electron superatom quantum system with hybridized $\mathrm{Ag}$ and water $\mathrm{O}$ orbitals delocalized over the cluster. Upon excitation, one electron of the s-type highest occupied molecular orbital is promoted to the p-type lowest unoccupied molecular orbitals and relaxes through enhanced intersystem crossing into long-lived triplet states.

F ew-atom luminescent silver clusters (AgCLs) (I) stabilized through organic (such as peptides, proteins, polymers, and DNA) (2-6) or inorganic (such as glasses and zeolites) (7-9) templates have emerged as promising candidates for a broad range of applications in lighting, imaging, sensing, and therapeutics (4). Compared with conventional quantum dots, few-atom AgCLs combine an ultrasmall size with excellent sizedependent photoluminescence (PL) spanning the ultraviolet to near-infrared spectrum. Strong quantum confinement of $\mathrm{Ag}$ valence electrons appears to break up the continuous density of states into discrete energy levels and confer molecularlike properties to the AgCLs. Nevertheless, the lack of a detailed understanding of the fundamental photophysical mechanisms underlying their emissions is hampering the rational design of AgCLs with improved and tailored optical properties. Atomic structures for AgCLs have not been determined unambiguously because of their vast distribution of size, environment, and tem-

Laboratory of Solid State Physics and Magnetism, KU Leuven, Celestijnenlaan 200D, B-3001 Leuven, Belgium. ${ }^{2}$ Molecular Visualization and Photonics, KU Leuven, Celestijnenlaan 200F, B-3001 Leuven, Belgium. ${ }^{3}$ Faculty of Chemistry, Hanoi National University of Education, 136 Xuan Thuy, Hanoi, Vietnam. ${ }^{4}$ Department of Chemistry, KU Leuven, Celestijnenlaan 200F, B-3001 Leuven, Belgium. ${ }^{5}$ Dipartimento di Scienza dei Materiali, Università di Milano-Bicocca, via Cozzi, 55, 20125 Milano, Italy. ${ }^{6}$ Consiglio Nazionale delle Ricerche-Istituto Officina dei Materiali-Operative Group in Grenoble (CNR-IOM-OGG), European Synchrotron Radiation Facility (ESRF) LISA Collaborating Research Group, Grenoble, France. 'Dutch-Belgian beamline, ESRF-The European Synchrotron, CS 40220, 38043 Grenoble, France. ${ }^{8}$ Centre for Surface Chemistry and Catalysis, KU Leuven, Celestijnenlaan 200F, B-3001 Leuven, Belgium.

*Corresponding author. Email: didier.grandjean@kuleuven.be (D.G.); maarten.roeffaers@kuleuven.be (M.B.J.R.); peter. lievens@kuleuven.be (P.L.) plate interactions, as well as the presence of a large fraction of nonluminescent $\mathrm{Ag}$ species.

The AgCLs that self-assemble in the cavities of the rigid aluminosilicate crystalline framework of zeolites have the most homogeneous and efficient emissions. The PL of AgCLs confined in thermally activated Ag-loaded zeolite structures of faujasite (FAU) and Linde Type A (LTA) topologies features tunable absorption and emission, large Stokes shifts, and exceptionally high external luminescence quantum efficiencies reaching unity $(8,10)$. However, the structure of these AgCLs has not been fully elucidated yet because of the complexity of Ag-zeolite host-guest interactions and the sensitivity of Ag-zeolite composites toward radiation (electrons and photons) used in structural characterization techniques (11). We present a detailed investigation of the structural and electronic properties of partially Ag-exchanged $\mathrm{Ag}_{3} \mathrm{~K}_{9}$-LTA zeolite by use of three complementary techniques. This system was selected for its green PL featuring an excellent external luminescence quantum yield of $23 \%$ among the Ag-LTA zeolites, its good stability toward x-ray irradiation (11), and its simpler crystallographic structure than that of FAU. With x-ray excited optical luminescence (XEOL), the x-ray absorption fine structure (EXAFS) signal is detected exclusively from the $\mathrm{Ag}$ atom fraction involved in the PL process at the $\mathrm{Ag} \mathrm{K}$-edge, thus selectively determining the structure of the emitting $\mathrm{Ag}$ species (12). This univocal assignment could not be made in earlier work (10); hence, approach may provide more detailed understanding of luminescent properties for a variety of few-atom $\mathrm{Ag}$ clusters. The structures obtained experimentally were confirmed computationally with geometry optimizations by using density functional theory (DFT) methods, while time-dependent DFT (TD-DFT) was applied to determine the electronic transitions responsible for the absorption and emission spectra of the stable isomers. Last, to confirm the electronic structure of the theoretically modeled AgCLs, we identified the relevant decay modes and time scales involved in the absorption and luminescence processes of $\mathrm{Ag}_{3} \mathrm{~K}_{9}$-LTA using a combination of femto- to millisecond time-resolved spectroscopies.

The large number of structural characterizations of AgCLs stabilized in LTA zeolites, often performed by means of $x$-ray diffraction and electron spin resonance (13-16), have led to numerous incomplete and often contradictory structural models. $\mathrm{Ag}_{3-4}$ clusters were tentatively related to partially Ag-exchanged LTA zeolites, whereas $\mathrm{Ag}_{6}$ clusters were associated to fully exchanged samples. High-resolution transmission electron microscopy (HRTEM) revealed octahedral $\mathrm{Ag}_{6}$ clusters in the sodalite cages of fully exchanged Ag-LTA zeolites (17), but no evidence linking this structure to the PL was given. Similar analysis of partially exchanged Ag-LTA zeolites remained unsuccessful because of the strong influence of electron-beam irradiation $(17,18)$.

EXAFS (19) provides information on cluster size and atom bonding both for the emissive and nonemissive clusters (20). By contrast, XEOL exclusively detects the XAFS signal from the atoms constituting the emissive species $(12,21,22)$. Also, although x-ray irradiation can affect the structure of few-atom clusters (11), XEOL would monitor any beam degradation effect (supplementary materials). The three-dimensional (3D) structures of the AgCLs were determined by combining the fitting results of the XEOL and transmission-detected EXAFS collected simultaneously (table S1).

We primarily analyzed the XEOL-detected EXAFS of $\mathrm{Ag}_{3} \mathrm{~K}_{9}$-LTA. The $\chi(\mathrm{k}) \mathrm{k}^{3}$-weighted EXAFS data and the corresponding phasecorrected Fourier transform (FT) best fits are shown in Fig. 1, A and B.

The first and second peaks of the FT were fitted with, respectively, two oxygen $(\mathrm{O})$ atoms at $2.36 \AA(\mathrm{N} 1)$ and three $\mathrm{Ag}$ atoms at $2.82 \AA$ (N2). Additionally, the fit was completed with two longer shells consisting of $0.4 \mathrm{~K}$ at $3.05 \AA$ (N4) and $1.1 \mathrm{Ag}$ at $3.3 \AA$ (N5). The Ag atoms coordinated to three other $\mathrm{Ag}$ atoms $\left(\mathrm{Ag}_{\mathrm{C}}\right)$ form tetrahedralike $\mathrm{Ag}_{4}$ clusters located inside the sodalite cage, as was shown with TEM (17). The $\mathrm{Ag}_{\mathrm{C}}$ atoms are each coordinated to two $\mathrm{O}$ atoms likely corresponding to extra-framework water molecules because of the short Ag-O distances and the fact that these $\mathrm{O}$ atoms are removed with a concomitant loss of the sample PL upon dehydration of the material (supplementary materials). The absence of contributions from the sodalite atoms $[\mathrm{O}$, silicon $(\mathrm{Si})$, and aluminum $(\mathrm{Al})]$ embedding AgCLs in the EXAFS signal is discussed in the supplementary materials.

The analysis of the XEOL-detected signal shows that the species at the origin of the brightgreen PL observed in $\mathrm{Ag}_{3} \mathrm{~K}_{9}$-LTA are $\mathrm{Ag}_{4}$ clusters with short $\mathrm{Ag}-\mathrm{Ag}$ distances of $2.82 \AA$, in which each $\mathrm{Ag}$ atom is bound to two water molecules at $2.36 \AA$. They are further surrounded by isolated $\mathrm{K}$ 
and Ag cations likely positioned in the single sixmembered rings (S6Rs) of the same sodalite cage. A twofold coordination of $\mathrm{Ag}_{\mathrm{C}}$ atoms, however, does not correspond to an integer number of water molecules but rather to two different stoichiometries of $x=2$ and $x=4$, corresponding to a water coordination per $\mathrm{Ag}_{\mathrm{C}}$ of 1.5 and 3 , respectively. This analysis suggests the presence of a mixture of $\mathrm{Ag}_{4}\left(\mathrm{H}_{2} \mathrm{O}\right)_{4}$ and $\mathrm{Ag}_{4}\left(\mathrm{H}_{2} \mathrm{O}\right)_{2}$ with a $\sim 34 / 66$ ratio $(3 \times 0.34+1.5 \times 0.66=2)$. Attempts to use other models for analyzing the XEOLdetected signal, including the structure used for the analysis of the transmission-detected EXAFS presented below, were either not successful or led to unrealistic fitting parameters (supplementary materials).

We also analyzed the transmission-detected EXAFS collected simultaneously with the XEOLdetected data. The $\chi(\mathrm{k}) \mathrm{k}^{3}$-weighted EXAFS data and the phase-corrected FT best fits of heattreated $\mathrm{Ag}_{3} \mathrm{~K}_{9}$-LTA are shown in Fig. 1, C and D. The distinct profiles compared with those collected with XEOL detection indicate that two different average local environments of $\mathrm{Ag}$ atoms were measured simultaneously, which is consistent with the x-ray absorption near-edge structure analysis (supplementary materials).

The first peak in the FT was fit with $2.5 \mathrm{O}$ at $2.34 \AA$ (N1) corresponding to the combination of the framework $\mathrm{O}\left(\mathrm{O}_{\mathrm{F}}\right)$ from the S6Rs rings and the $\mathrm{H}_{2} \mathrm{O}$ ligands, as shown in the XEOL analysis. The second peak in the FT is a multipeak composed of $2.6 \mathrm{Si} / \mathrm{Al}$ atoms (N2) at 3.26 to $3.30 \AA$ corresponding to a fraction of nonluminescent $\mathrm{Ag}$ cations located near the center of the S6Rs $\left(\mathrm{Ag}_{\mathrm{R}}\right)$ (fig. S13), not detected in XEOL-EXAFS. The second peak in the FT analysis also contained a weaker $\mathrm{Ag}-\mathrm{Ag}$ contribution (N3) of $1.7 \mathrm{Ag}$ at unusually short distances of $2.70 \AA$. This feature corresponds to the remaining part of the silver atoms $\mathrm{Ag}_{\mathrm{C}}(\sim 57 \%)$ that are coordinated to $\sim 3(1.7 / 0.57)$ silver neighbors and are forming $\mathrm{Ag}_{4}$ clusters inside the sodalite cage. The $4 \%$ discrepancy between the $\mathrm{Ag}_{\mathrm{C}}-\mathrm{Ag}_{\mathrm{C}}(2.70$ to $2.82 \AA$ ) distances found by the two detection approaches suggests that XEOL measured preferentially the excited state structure of the clus- ters (supplementary materials). $\mathrm{Ag}_{\mathrm{C}}$ in $\mathrm{Ag}_{4}$ clusters are coordinated to $2.1 \mathrm{O}(1.2 / 0.57)$ from water molecules. Additionally, four shells $\left(\mathrm{N}_{4}\right.$ to $\left.\mathrm{N}_{7}\right)$ consisting of $\mathrm{K}$ and $\mathrm{Ag}$ were detected at liquidnitrogen temperatures between 2.97 and $4.49 \AA$ corresponding to $\mathrm{Ag}_{\mathrm{C}}-\mathrm{K}$ or $\mathrm{Ag}_{\mathrm{C}}-\mathrm{Ag}_{\mathrm{R}}$ distances from basal $\mathrm{Ag}_{\mathrm{C}}$ in $\mathrm{Ag}_{4}$ tetrahedra associated with the absence or presence, respectively, of a water molecule sandwiched between the two atoms (fig. S13). These shells are complemented by two long-distance contributions $\left(\mathrm{N}_{8}\right.$ and $\left.\mathrm{N}_{9}\right)$ corresponding to $\mathrm{Ag}_{\mathrm{C}}-\mathrm{Ag}_{\mathrm{R}}$ from apical $\mathrm{Ag}_{\mathrm{C}}$ in $\mathrm{Ag}_{4}$ tetrahedra and $\mathrm{Ag}_{\mathrm{R}}-\mathrm{Ag}_{\mathrm{R}}$ (fig. S7a) detected at 5.24 and $6.13 \AA$ at LN. The distinct combination of distances of $\mathrm{N}_{4}$ to $\mathrm{N}_{9}$ shells closely fit the Ag-LTA sodalite crystallographic model (fig. S7B), fully supporting the AgCL local structures proposed.

The EXAFS investigation shows that the emitters in $\mathrm{Ag}_{3} \mathrm{~K}_{9}$-LTA consist of $\sim 40 \%$ of $\mathrm{Ag}_{4}\left(\mathrm{H}_{2} \mathrm{O}\right)_{4}$. and $60 \%$ of $\mathrm{Ag}_{4}\left(\mathrm{H}_{2} \mathrm{O}\right)_{2}$ tetrahedra-like clusters located at the center of the sodalite cage. These structures are presented in Fig. 1, E to J. The clusters are coordinated at their faces by two or four water molecules located near the center of the S6Rs and sandwiched between three $\mathrm{Ag}_{\mathrm{C}}$ and one $\mathrm{Ag}_{\mathrm{R}}$ (or $\mathrm{K}$ cation). AgCLs consisting of $57 \%$ of the total number of exchanged $\mathrm{Ag}$ atoms are mostly surrounded by the remaining $43 \%$ isolated $\mathrm{Ag}_{\mathrm{R}}$ cations plus some additional $\mathrm{K}$ cations in the S6Rs. This indicates that $\mathrm{Ag}$ cations in partially exchanged $\mathrm{Ag}_{3} \mathrm{~K}_{9}$-LTA concentrate (six to seven $\mathrm{Ag}$ atoms instead of three expected from the $\mathrm{Ag}$ stoichiometry) in a limited fraction of the sodalite cages $(\sim 45 \%)$. (23).

We used a combination of DFT and TD-DFT to model AgCLs and probed their charges with the natural bonding orbital approach. Two stable isomers- $\left[\mathrm{Ag}_{4}\left(\mathrm{H}_{2} \mathrm{O}\right)_{x}\left(\mathrm{Si}_{24} \mathrm{H}_{24} \mathrm{O}_{36}\right)\right], x=2$ and $x=4$, showing the best agreement between calculated and measured structures and absorption spectrawere obtained when applying $\mathrm{a}+2$ charge preferentially localized on the $\mathrm{Ag}_{4} \mathrm{CLs}$ but extending toward the cluster surrounding (tables S4 and S5). The doubly charged $\mathrm{Ag}_{4} \mathrm{CLs}$ exhibit a closedshell electronic configuration, in which the $\mathrm{Ag} 4 \mathrm{~d}$ shell is completely filled, and the two remaining valence $5 \mathrm{~s}$ electrons are delocalized over the cluster. Within a superatom model, two electrons associated to a metal cluster correspond to the smallest magic number with enhanced stability $(24,25)$, which is consistent with analogous theoretical work on $\mathrm{Ag}_{4} \mathrm{CLs}(26,27)$.

Both isomers $\left[\mathrm{Ag}_{4}\left(\mathrm{H}_{2} \mathrm{O}\right)_{\mathrm{x}}, x=2\right.$ and 4$]$ consist of pseudotetrahedral $\mathrm{Ag}_{4}$ clusters located, unlike the experimental structures, in an off-centered position in the sodalite cage, with one or two $\mathrm{Ag}$ atoms coordinated directly to $\mathrm{O}_{\mathrm{F}}$ (supplementary materials). In $\mathrm{Ag}_{4}\left(\mathrm{H}_{2} \mathrm{O}\right)_{4}$, each $\mathrm{Ag}$ atom is coordinated on average to two $\mathrm{O}$ atoms (water plus $\mathrm{O}_{\mathrm{F}}$ ) with an average $\mathrm{Ag}-\mathrm{Ag}$ bond distance of $\sim 2.79$ and $2.92 \AA$ in the ground and excited state, respectively (fig. S14). In $\mathrm{Ag}_{4}\left(\mathrm{H}_{2} \mathrm{O}\right)_{2}$, an average $\mathrm{Ag}$ - $\mathrm{Ag}$ distance of $2.87 \AA$ in the ground state and a mean $O$ coordination close to 1.3 were obtained (fig. S15). These calculated structures featuring a $5 \%$ increase in the $\mathrm{Ag}_{\mathrm{C}}-\mathrm{Ag}_{\mathrm{C}}$ distances from the ground to the excited states are in good agreement with the experimental results (supplementary materials).

The calculated frontier orbitals for both $\mathrm{Ag}_{4}\left(\mathrm{H}_{2} \mathrm{O}\right)_{4}{ }^{2+}$ and $\mathrm{Ag}_{4}\left(\mathrm{H}_{2} \mathrm{O}\right)_{2}{ }^{2+}$ isomers (Fig. $2 \mathrm{~A}$ and fig. S16, respectively) are composed of a contribution of $\sim 50 \%$ from $\mathrm{Ag} 5 \mathrm{~s}$ atomic orbitals and of up to $25 \%$ from the $\mathrm{O}$ states of the surrounding $\mathrm{O}_{\mathrm{F}}$ and $\mathrm{H}_{2} \mathrm{O}$, as shown in the density of states curves (fig. S18). A doubly occupied HOMO of totally symmetric s-type orbital forms the ground state $\left({ }^{1} \mathrm{~S}_{0}\right)$ and two sets of three singlet $\left({ }^{1} \mathrm{P}\right)$ and three triplet $\left({ }^{3} \mathrm{P}\right)$ LUMOs consisting of one-node p-type orbitals form the expected lowest-lying cluster orbitals for a cluster system with two skeleton electrons. Both states in each isomer have similar atomic orbital compositions (fig. S18), suggesting that the excitations are mainly localized on the cluster.

The key role of water ligands in AgCLs' electronic properties is highlighted in the energy level diagram (Fig. 2B and fig. S17) of $\mathrm{Ag}_{4}\left(\mathrm{H}_{2} \mathrm{O}\right)_{4}{ }^{2+}$ and $\mathrm{Ag}_{4}\left(\mathrm{H}_{2} \mathrm{O}\right)_{2}{ }^{2+}$ along with water-free $\mathrm{Ag}_{4}{ }^{2+}$ clusters as reference. In water-free unperturbed $\mathrm{Ag}_{4}{ }^{2+}$, the ground state is the $\mathrm{HOMO}^{1} \mathrm{~S}_{0}$, and the LUMOs consist of threefold degenerated singlet ${ }^{1} \mathrm{P}$ and triplet ${ }^{3} \mathrm{P}$ excited states. Upon coordination with water, the ligand field lifts the degeneracy of the

\section{Fig. 1. Ag K-edge XEOL and transmission-detected EXAFS and FTs of heat- treated $\mathrm{Ag}_{3} \mathrm{~K}_{\mathbf{9}}$-LTA and} derived structures.

(A) XEOL-detected and (C) transmission-detected $\mathrm{k}^{3}$-weighted Ag K-edge EXAFS with the (B) phasecorrected XEOL-detected FT and (D) transmissiondetected FT best fits. (E to J) Structures of (E) $\mathrm{Ag}_{4}\left(\mathrm{H}_{2} \mathrm{O}\right)_{4}$ and $(\mathrm{H}) \mathrm{Ag}_{4}\left(\mathrm{H}_{2} \mathrm{O}\right)_{2}$, including $[(\mathrm{F})$ and $(\mathrm{I})] \mathrm{Ag}_{\mathrm{R}}$ cations and $[(G)$ and $(J)]$ embedded in the sodalite cage ( $0.66 \mathrm{~nm}$ free diameter).
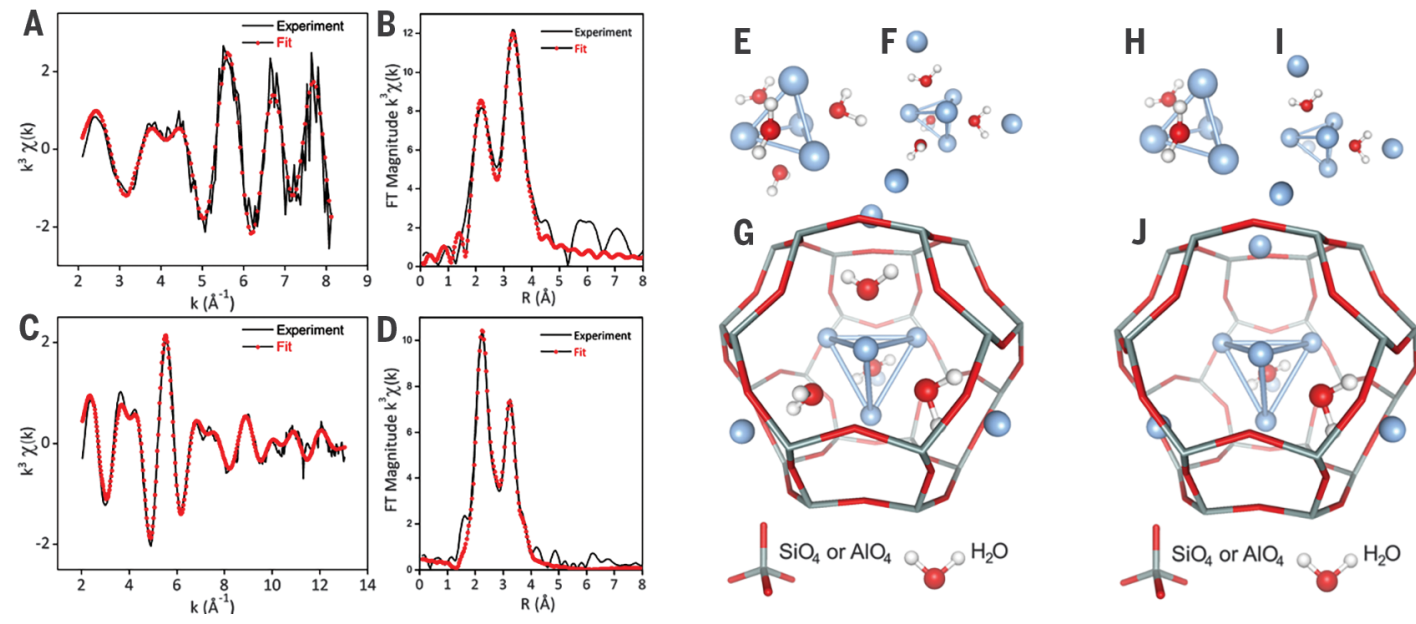
LUMOs into six excited states: three singlet ${ }^{1} \mathrm{P}$ [total spin quantum number $(S)=0$; total orbital angular momentum quantum number $(L)=1$; magnetic quantum number $\left(m_{1}\right)=-1,+1$, or 0 ) and three triplet ${ }^{3} \mathrm{P}\left(S=1 ; L=1 ; m_{1}=-1,+1\right.$, or 0$)$ states. The absorption occurs from the ground state corresponding to two electrons of opposite spins on a HOMO $s$-like orbital $\left({ }^{1} \mathrm{~S}_{0}\right)$ to the singlet excited states ${ }^{1} \mathrm{P}(3.5$ and $3.7 \mathrm{eV})$ that correspond to one electron on a $s$-like orbital and one electron on LUMO, LUMO+1, or LUMO+2 $p$ like orbitals, with the two electrons having opposite spins.

These transitions feature large oscillator strengths $f$ because they are allowed by spin and angular momentum selection rules. The strong overlap of the high-energy triplet ${ }^{3} \mathrm{P}(S=1, L=1$, $m_{1}=0$ ) state with the ${ }^{1} \mathrm{P}$ singlet states ensures, in combination with large spin-orbit coupling expected for Ag, an enhanced intersystem crossing. Upon light excitation, a fraction of ${ }^{1} \mathrm{P}$ singlet states population is transferred to the highenergy triplet state that finally decays into the low-lying ${ }^{3} \mathrm{P}\left(S=1, L=1, m_{1}=-1\right.$ or +1$)$ triplet state. As shown in Fig. 2B, the intensity of the ligand-field splitting of the p-like LUMOs is directly proportional to the number of water molecules coordinating AgCLs, decreasing the band gap when going from $\mathrm{Ag}_{4}\left(\mathrm{H}_{2} \mathrm{O}\right)_{2}{ }^{2+}$ to $\mathrm{Ag}_{4}$ $\left(\mathrm{H}_{2} \mathrm{O}\right)_{4}{ }^{2+}$ isomers. The bright-green emission of $\mathrm{Ag}_{4}\left(\mathrm{H}_{2} \mathrm{O}\right)_{4}{ }^{2+}$ then occurs from the lowest-lying ${ }^{3} \mathrm{P}$ triplet excited state ${ }^{3} \mathrm{P}\left(S=1, L=1, m_{1}=-1\right)$ to the ground state ${ }^{1} \mathrm{~S}_{0}$.

The modeled absorption spectra for the $\mathrm{Ag}_{4}\left(\mathrm{H}_{2} \mathrm{O}\right)_{4}{ }^{2+}$ and $\mathrm{Ag}_{4}\left(\mathrm{H}_{2} \mathrm{O}\right)_{2}{ }^{2+}$ isomers (Fig. 3) are in excellent agreement with the steady-state optical experimental data. Calculated absorption peaks found at 343 and $320 \mathrm{~nm}$ in $\mathrm{Ag}_{4}\left(\mathrm{H}_{2} \mathrm{O}\right)_{4}{ }^{2+}$ and $\mathrm{Ag}_{4}\left(\mathrm{H}_{2} \mathrm{O}\right)_{2}{ }^{2+}$, respectively, closely match the experimental excitation peaks at $340 \mathrm{~nm}(3.64 \mathrm{eV})$ and $310 \mathrm{~nm}(4.00 \mathrm{eV})$. These results also confirm the assumption that the $37 / 63$ intensity ratio of the two main emission peaks is directly related to the 34/66 fraction ratio of $\mathrm{Ag}_{4}\left(\mathrm{H}_{2} \mathrm{O}\right)_{4}$ and $\mathrm{Ag}_{4}\left(\mathrm{H}_{2} \mathrm{O}\right)_{2}$ present in $\mathrm{Ag}_{3} \mathrm{~K}_{9}$-LTA composites. Last, the green PL energy obtained experimentally at $550 \mathrm{~nm}$ $(2.25 \mathrm{eV})$ fits the transition energy of $556 \mathrm{~nm}$ $(2.23 \mathrm{eV})$ of the modeled transition from the relaxed lowest-lying ${ }^{3} \mathrm{P}$ triplet excited state to the ${ }^{1} \mathrm{~S}_{0}$ ground state (Fig. 2B).

To determine the decay time scale and energies of $\mathrm{Ag}_{3} \mathrm{~K}_{9}$-LTA modeled optical transitions and to verify the triplet nature of its bright green PL, we performed a global analysis of the decays obtained with femtosecond fluorescence upconversion, time-correlated single-photon counting (TCSPC) and nanosecond luminescence time-resolved spectroscopies. Decays obtained with femtosecond fluorescence up-conversion in the range of 410 to $570 \mathrm{~nm}$ reveal three time components of 0.5 and 2.6 ps related to relaxation processes and $>50$ ps attributed to the ${ }^{1} \mathrm{P}-{ }^{-}{ }^{-}{ }^{1} \mathrm{~S}_{0}$ transition (Fig. 4, A and B; fig. S24, decay traces; and table S7). The amplitude-to-wavelength dependence (AWD) of the first two ultrafast components (maxima centered at 510 and $530 \mathrm{~nm}$ ) are slightly blue-shifted relative to the maximum
A

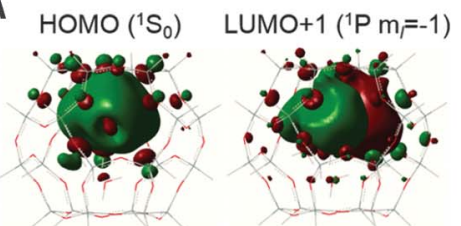

LUMO ( $\left.{ }^{1} \mathrm{P} \mathrm{m}_{\mathrm{f}}=+1\right) \quad$ LUMO+2 $\left({ }^{1} \mathrm{P} \mathrm{m}_{\mathrm{f}}=0\right)$

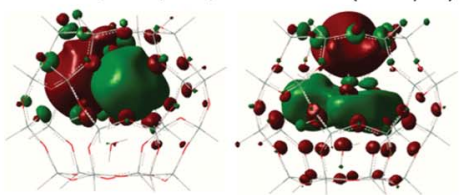

B

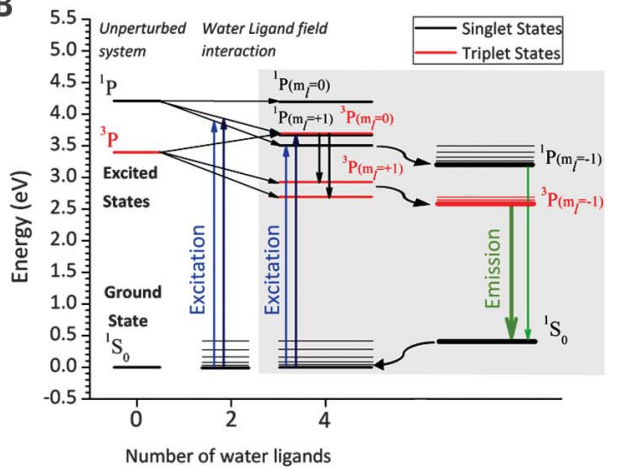

Fig. 2. Frontier orbitals of $\left[\mathrm{Ag}_{4}\left(\mathrm{H}_{2} \mathrm{O}\right)_{4}\left(\mathrm{Si}_{24} \mathrm{H}_{24} \mathrm{O}_{36}\right)\right]^{2+}$ and energy level diagram of $\mathrm{Ag}_{4}\left(\mathrm{H}_{2} \mathrm{O}\right)_{2}{ }^{2+}$ and $\mathbf{A g}_{4}\left(\mathrm{H}_{2} \mathrm{O}\right)_{4}{ }^{2+}$ clusters in $\mathbf{A g}_{3} \mathrm{~K}_{9}$-LTA. (A) Frontier orbitals consist of one single symmetric s-type $\mathrm{HOMO}\left({ }^{1} \mathrm{~S}_{0}\right)$ and three singlet one-node $\mathrm{p}$-type ${ }^{1} \mathrm{P}\left(m_{\mathrm{l}}=-1,+1\right.$, or 0$)$ LUMOs $\left(p_{x}, p_{y}, p_{z}\right)$ delocalized over all the $\mathrm{Ag}$ and $\mathrm{O}$ atoms of the cluster. Atom colors are $\mathrm{Si}$, gray; $\mathrm{O}$, red; $\mathrm{Ag}$, blue; hydrogen, white. (B) Energy level diagram showing the ground-state ${ }^{1} \mathrm{~S}_{0}$ and the excited states ${ }^{3} \mathrm{P}$ and ${ }^{1} \mathrm{P}$ of water-free unperturbed $\mathrm{Ag}_{4}{ }^{2+}$ clusters and the ground-state ${ }^{1} \mathrm{~S}_{0}$ and the six singlet ${ }^{1} \mathrm{P}$ and triplet ${ }^{3} \mathrm{P}$ excited states of $\mathrm{Ag}_{4}\left(\mathrm{H}_{2} \mathrm{O}\right)_{2}{ }^{2+}$ and $\mathrm{Ag}_{4}\left(\mathrm{H}_{2} \mathrm{O}\right)_{4}{ }^{2+}$ perturbed by means of water ligand field interaction. Blue arrows represent the allowed transitions, and the green arrows represent the luminescent transitions between the relaxed states.

of the steady-state emission spectrum $(550 \mathrm{~nm})$, suggesting the rapid depopulation of ${ }^{1} \mathrm{P}(S=0$; $\left.L=1 ; m_{1}=-1,+1\right)$ singlet excited states. These ultrafast components attributed to nonfluorescent short-lived intermediate species formed after the relaxation of ${ }^{1} \mathrm{P}$ Franck-Condon states match closely the energy of the ${ }^{1} \mathrm{P}\left(S=0, L=1, m_{1}=-1\right)$ to- ${ }^{-} \mathrm{S}_{0}$ transition predicted with TD-DFT (Fig. $2 \mathrm{~B}$ ). These intermediate states rapidly convert into fluorescent ${ }^{3} \mathrm{P}$ triplet states lying at similar energies via intersystem crossing (Fig. 4, B and D).

This model is confirmed through the analysis of the PL decays in the micro- to millisecond range that reveal three time constants of $423 \mathrm{~ns}$, $10.6 \mu \mathrm{s}$, and $116 \mu \mathrm{s}$. On the basis of the AWD presented in Fig. 4C, the 423-ns component is attributed to an excited state with an intense emission peaking at 520 to $540 \mathrm{~nm}(2.38$ to $2.30 \mathrm{eV})$, with estimated radiative and nonradiative rates of $5.43 \times 10^{5} \mathrm{~s}^{-1}$ and $18.2 \times 10^{5} \mathrm{~s}^{-1}$, respectively. The close resemblance of the AWD of this state with the stationary emission spectrum indicates that these long-lived species are at the origin of the bright-green emission observed in $\mathrm{Ag}_{3} \mathrm{~K}_{9}$-LTA. This emission occurring from long-lived states characteristic for spin-forbidden transitions points toward their peculiar triplet nature. The other decay times of 10.6 and $118 \mu \mathrm{s}$ are attributed to two different triplet excited states, with weak emissions centered at 630 and $680 \mathrm{~nm}$ (1.97 and $1.82 \mathrm{eV}$ ), respectively (Fig. 2B; fig. S25, decay traces; and table $\mathrm{S} 8$ ), which are associated with the presence of residual amounts of emissive species such as AgCLs with different size and/or water coordination (10).

The triplet nature of $\mathrm{Ag}_{3} \mathrm{~K}_{9}$-LTA bright-green emission is further corroborated by the remarkable enhancement of the PL accompanied by a dramatic increase of the decay time from $423 \mathrm{~ns}$ to $106 \mu$ s for the $540-\mathrm{nm}$ main emission at low temperature $(77 \mathrm{~K})$, whereas the faster components remained mostly unaffected (figs. S26 to S33).
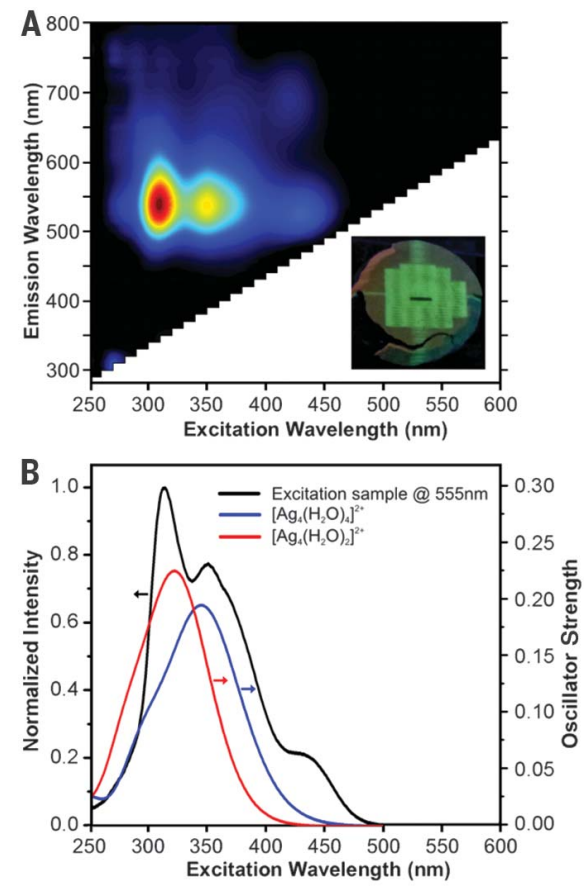

Fig. 3. Steady-state excitation-emission of $\mathbf{A g}_{\mathbf{3}} \mathbf{K}_{\mathbf{9}}$-LTA. (A) 2D excitation-emission plot. (Inset) The picture of an $\mathrm{x}$-ray-irradiated sample under $366 \mathrm{~nm}$ illumination. (B) Excitation spectrum $\lambda_{\text {detection }}=555 \mathrm{~nm}$ of as-prepared $\mathrm{Ag}_{3} \mathrm{~K}_{9}-\mathrm{LTA}$. Calculated ${ }^{1} \mathrm{~S}_{0} \mathrm{HOMO}$ to ${ }^{1} \mathrm{P}(\mathrm{S}=0$; $\left.L=1 ; m_{1}=-1,+1\right)$ LUMOs absorption spectra of $x=2$ and $x=4\left[\mathrm{Ag}_{4}\left(\mathrm{H}_{2} \mathrm{O}\right)_{\mathrm{x}}\right]^{2+}$ isomers showing a good agreement with experiments.

This result shows that excited-state kinetics, in which nonradiative decay channels are hindered at low temperature and characteristic of tripletstate emissions, is involved. Hence, given the close correspondence between the computational and 

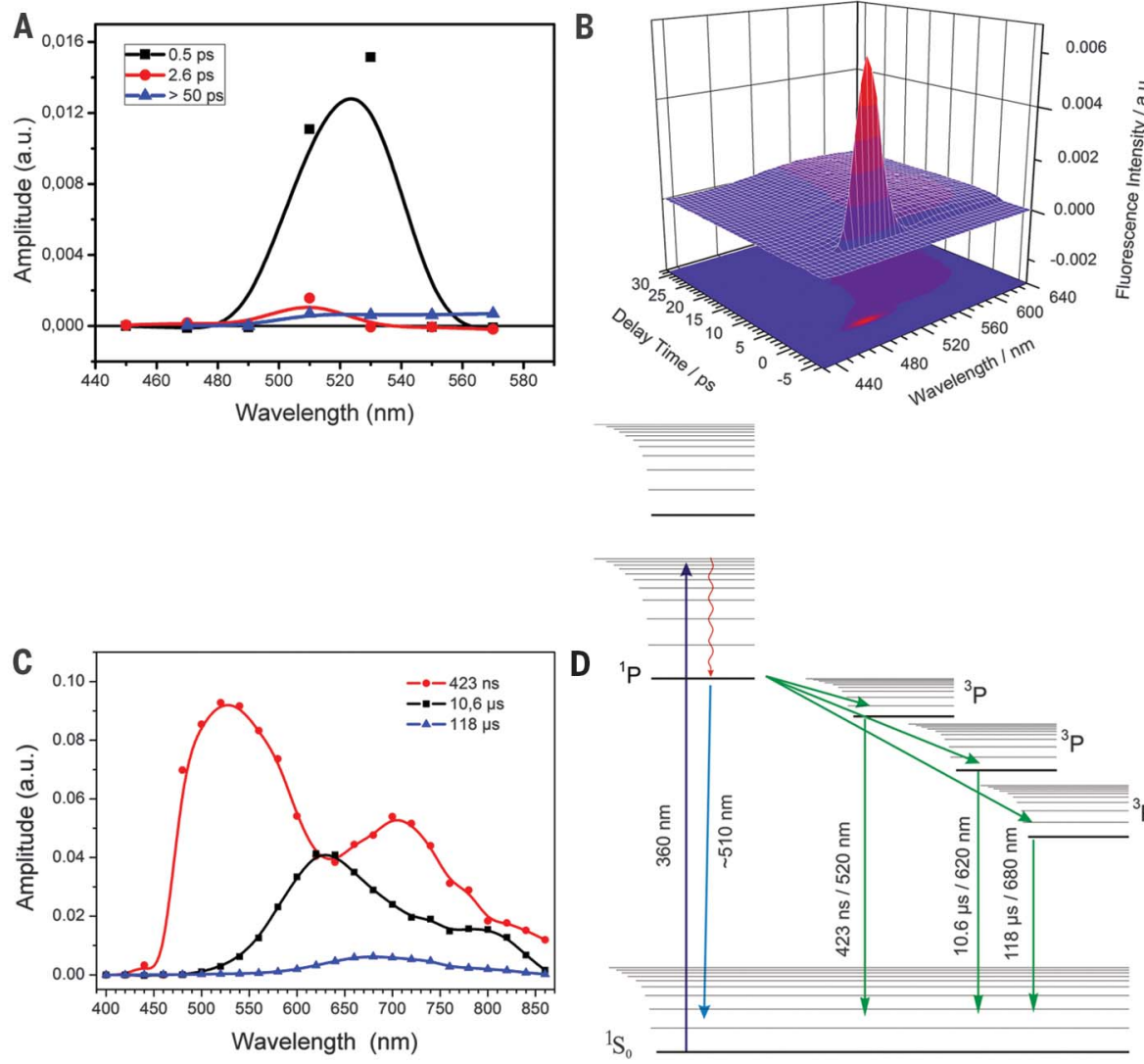

Fig. 4. Time-resolved spectroscopy of $\mathbf{A g}_{\mathbf{3}} \mathbf{K}_{\mathbf{9}}$-LTA. (A and $\mathbf{B}$ ) AWD 3D time-resolved fluorescence emission spectra in 50-ps time window obtained with (C) femtosecond fluorescence up-conversion, in 1-ms time window through nanosecond luminescence. (D) Schematic illustration of the main electronic states involved as a function of energy (on the vertical axis).

the photophysics results, the cluster-ligand interaction as included in the model of a two-electron doubly charged $\mathrm{AgCL}$, possibly with a fraction of the charge located on the sodalite cage, explains the occurrence of long-lived bright luminescent states in $\mathrm{Ag}_{3} \mathrm{~K}_{9}$-LTA.

By measuring exclusively the local structure of the emissive Ag clusters in partially exchanged LTA zeolites, XEOL-XAFS has allowed for the first time the unambiguous identification of their functional structures. DFT modeling based on these detailed structures showed that the double positively charged $\mathrm{Ag}_{4}\left(\mathrm{H}_{2} \mathrm{O}\right)_{4}$ and $\mathrm{Ag}_{4}\left(\mathrm{H}_{2} \mathrm{O}\right)_{2}$ clusters, in which water ligand molecules modulate the HOMO-LUMO gap, behave as confined twoelectron helium or alkaline earth-like superatom quantum systems that mainly emit via their longlived lowest-lying ${ }^{3} \mathrm{P}$ triplet excited state, as confirmed with time-resolved optical spectroscopy. We anticipate that similar photophysical properties may also apply to luminescent AgCLs con- fined in other inorganic and organic scaffolds. This is likely the case for AgCLs confined in fully exchanged LTA or in FAU zeolites that possess very similar structural and luminescent properties (10). This new understanding of the mechanism of AgCLs' bright luminescence and its expected dependence on the interaction with oxygen ligands, electron confinement, electrostatic interaction, and charge transfer to the surrounding silver atoms, which differ from the single $\mathrm{Ag}$ cations emission model proposed earlier (28-30), should lead to substantial improvements in the rational design of AgCLs optical properties.

\section{REFERENCES AND NOTES}

1. L. A. Peyser, A. E. Vinson, A. P. Bartko, R. M. Dickson, Science 291, 103-106 (2001)

2. C. I. Richards et al., J. Am. Chem. Soc. 130, 5038-5039 (2008).

3. T. Vosch et al., Proc. Natl. Acad. Sci. U.S.A. 104, 12616-12621 (2007).

4. Y. Yu, B. Y. L. Mok, X. J. Loh, Y. N. Tan, Adv. Healthc. Mater. $\mathbf{5}$ 1844-1859 (2016).
5. I. Díez et al., Nanoscale 4, 4434-4437 (2012).

6. J. Yu, S. A. Patel, R. M. Dickson, Angew. Chem. Int. Ed. 46, 2028-2030 (2007).

7. A. Simo et al., J. Am. Chem. Soc. 134, 18824-18833 (2012).

8. G. De Cremer et al., J. Am. Chem. Soc. 131, 3049-3056 (2009)

9. A. S. Kuznetsov, V. K. Tikhomirov, M. V. Shestakov, V. V. Moshchalkov, Nanoscale 5, 10065-10075 (2013).

10. O. Fenwick et al., Nat. Mater. 15, 1017-1022 (2016).

11. E. Coutino-Gonzalez et al., Chem. Commun. (Camb.) 50 , 1350-1352 (2014)

12. T. K. Sham, Adv. Mater. 26, 7896-7901 (2014).

13. T. Sun, K. Seff, Chem. Rev. 94, 857-870 (1994).

14. P. A. Jacobs, J. B. Uytterhoeven, H. K. Beyer, J. Chem. Soc. Faraday Trans. I 75, 56 (1979)

15. J. Michalik, L. Kevan, J. Am. Chem. Soc. 108, 4247-4253 (1986)

16. P. J. Grobet, R. A. Schoonheydt, Surf. Sci. 156, 893-898 (1985).

17. A. Mayoral, T. Carey, P. A. Anderson, A. Lubk, I. Diaz, Angew. Chem. Int. Ed. 50, 11230-11233 (2011).

18. L. A. Bursill, J. M. Thomas, K. J. Rao, Nature 289, 157-158 (1981)

19. A. Baldansuren, H. Dilger, R. A. Eichel, J. A. van Bokhoven, E. Roduner, J. Phys. Chem. C 113, 19623-19632 (2009).

20. M. L. Neidig et al., J. Am. Chem. Soc. 133, 11837-11839 (2011)

21. L. Liu, T. K. Sham, W. Han, C. Zhi, Y. Bando, ACS Nano 5 , 631-639 (2011).

22. T. K. Sham, R. A. Rosenberg, ChemPhysChem 8, 2557-2567 (2007)

23. M. Meyer, C. Leiggener, G. Calzaferri, ChemPhysChem 6 , 1071-1080 (2005).

24. M. Walter et al., Proc. Natl. Acad. Sci. U.S.A. 105, 9157-9162 (2008).

25. T. Yumura, M. Kumondai, Y. Kuroda, T. Wakasugi, H. Kobayashi, RSC Advances 7, 4950-4959 (2017)

26. A. Kulesza et al., Angew. Chem. Int. Ed. 50, 878-881 (2011)

27. P. Schlexer, A. Ruiz Puigdollers, G. Pacchioni, Phys. Chem. Chem. Phys. 17, 22342-22360 (2015)

28. H. Lin, K. Imakita, M. Fujii, Appl. Phys. Lett. 105, 211903 (2014)

29. H. Lin et al., Nanoscale 7, 15665-15671 (2015).

30. R. Seifert, R. Rytz, G. Calzaferri, J. Phys. Chem. A 104 7473-7483 (2000).

\section{ACKNOWLEDGMENTS}

We thank B. Dieu for the graphical material. Funding: We acknowledge the IAP-7 (Belspo), the EU (FP7/2007-2013 and GA nos. 310651-SACS and 607417-Catsense), the Flemish government "Methusalem" (CASAS, Meth/08/04, CASAS2, and Meth/15/04), the SoPPoM program, the FWO (G.0990.11, G.0197.11, G.0962.13, G.0B39.15, and ZW1509 G0H6316N), and KU Leuven (GOA/14 and IDO/07/011). We thank the ESRF (CH-4207) and the staff of LISA-BM08 and DUBBLE-BM26A (26-01-865) beamlines. Author contributions: D.G. and P.L. conceived and directed the study. E.C.-G., W.B., and M.B.J.R. prepared the samples and performed the steady-state optical, elemental, and thermogravimetric analysis characterization. D.G., E.C.-G., F.D., D.B., W.B., and S.A. performed the XEOL-XAFS and Tr-XAFS measurements. D.G. and S.A. analyzed the XAFS data. N.T.C., P.S., and M.T.N. performed the DFT calculations. E.F. and J.H. designed, performed, and analyzed the time-resolved optical experiments. All authors contributed to discussions and interpretations of the combined experimental and theoretical results. D.G., P.L., E.F., and S.A. prepared the manuscript with contributions from all coauthors. All authors have approved the final version of the manuscript. Competing interests: None declared. Data and materials availability: All data needed to evaluate the conclusions in the paper are present in the paper or the supplementary materials.

\section{SUPPLEMENTARY MATERIALS}

www.sciencemag.org/content/361/6403/686/suppl/DC Materials and Methods

Supplementary Text

Figs. S1 to S35

Tables S1 to S8

References (31-45)

13 November 2017; accepted 15 June 2018

10.1126/science.aaq1308 


\section{Science}

\section{Origin of the bright photoluminescence of few-atom silver clusters confined in LTA zeolites}

Didier Grandjean, Eduardo Coutiño-Gonzalez, Ngo Tuan Cuong, Eduard Fron, Wouter Baekelant, Saleh Aghakhani, Philomena Schlexer, Francesco D'Acapito, Dipanjan Banerjee, Maarten B. J. Roeffaers, Minh Tho Nguyen, Johan Hofkens and Peter Lievens

Science 361 (6403), 686-690.

DOI: $10.1126 /$ science.aaq1308

\section{Unmasking the glow of silver clusters}

Small silver clusters stabilized by organic materials or inorganic surfaces can exhibit bright photoluminescence, but the origin of this effect has been difficult to establish, in part because the materials are heterogeneous and contain many larger but inactive clusters. Grandjean et al. studied silver clusters in zeolites, using x-ray excited optical luminescence to monitor only the emissive structures (see the Perspective by Quintanilla and Liz-Marzán). Aided by theoretical calculations, they identified the electronic states of four-atom silver clusters bound with water molecules that produce bright green emission--thus identifying candidate materials for application in lighting, imaging, and therapeutics.

Science, this issue p. 686 ; see also p. 645

ARTICLE TOOLS

SUPPLEMENTARY

MATERIALS

RELATED

CONTENT

REFERENCES

PERMISSIONS http://science.sciencemag.org/content/361/6403/686

http://science.sciencemag.org/content/suppl/2018/08/15/361.6403.686.DC1

http://science.sciencemag.org/content/sci/361/6403/645.full

This article cites 39 articles, 3 of which you can access for free http://science.sciencemag.org/content/361/6403/686\#BIBL

http://www.sciencemag.org/help/reprints-and-permissions

Use of this article is subject to the Terms of Service

Science (print ISSN 0036-8075; online ISSN 1095-9203) is published by the American Association for the Advancement of Science, 1200 New York Avenue NW, Washington, DC 20005. 2017 (C) The Authors, some rights reserved; exclusive licensee American Association for the Advancement of Science. No claim to original U.S. Government Works. The title Science is a registered trademark of AAAS. 